\title{
A Study on the Relationship Between ERP Logic and Direct Consume Coefficient of I/O Table
}

\author{
Lingling Zhang ${ }^{1}$, Jun $\mathrm{Li}^{2}$, Qin Wang ${ }^{3}$, Rencheng Tong ${ }^{4}$, Yuejin Zhang ${ }^{4}$ and \\ Xingsen $\mathrm{Li}^{4}$ \\ ${ }^{1}$ School of Management, Graduate University of Chinese Academy of Sciences, Chinese \\ Academy of Sciences, Research Center on Data Technology and Knowledge Economy, \\ Beijing, 100080, P.R. China zhangll@gucas.ac.cn \\ ${ }^{2}$ School of Management, Graduate University of Chinese Academy of Sciences, Chinese \\ Academy of Sciences; Research Center on Data Technology and Knowledge Economy, Beijing \\ 100080, P.R.. China lijun@huatai-serv.com \\ ${ }^{3}$ Institute of Computing Technology of the Chinese Academy of Sciences, Beijing 100080, \\ P.R. China wangqin@ict.ac.cn \\ ${ }^{4}$ School of Management, Graduate University of Chinese Academy of Sciences, Beijing \\ 100080, P.R. China tongrch@gucas.ac.cn zhangyuejin05@mails.gucas.ac.cn \\ lixingsen@126.com
}

\begin{abstract}
The paper analyzes necessity and possibility of integrating ERP with Input-Output technology (I/O). It studies relationship between ERP logic and the direct consume coefficient of manufacture enterprise $\mathrm{I} / \mathrm{O}$ table, and proves that it is feasible to convert basic data of ERP to direct consume coefficient and entire consume coefficient of enterprise $\mathrm{V} / \mathrm{O}$ table. It also proves that it is convenient to use ERP basic data to make manufacture enterprise $1 / O$ table, and to analyze and improve decision making.
\end{abstract}

Keywords: Workflow net (WF-net), Workflow model, Colored petri net, Agent, Workflow resource management, Business process analysis

\section{INTRODUCTION}

Enterprise Resource Planning, ERP, has been widely used by international manufacture enterprise as an information system recently. But, with the development of the innovation and technology progress, and the counterchange of the market demand, some function of traditional ERP can't satisfy the needs of a few enterprises. It mainly behaves like this, the operation model's dynamic ability to meet emergency and decision sustain is too bad, the building circle is too long, as well as the cost is too high. Those result in the difficult of the population and success of EPR.

In order to solve those problems, this paper brings forward some thinks about the applying of enterprise $\mathrm{V} / \mathrm{O}$ technology into ERP. Contrast ERP and enterprise I/O model, they have some communications in the referring objects, inside logic, main functions, and the ranger they deal with. For these reason they have the possibility to associative. But they emphasize particularly on different things. Thus, to apply the enterprise $\mathrm{I} / \mathrm{O}$ model into ERP have several advantages. On one hand, we can utilize

Please use the following format when citing this chapter:

Zhang, L., Li. J.. Wang. Q.. Tong. R.. Zhang, Y., Li, X., 2007, in IFIP International Federation for Information Processing, Volume 254, Research and Practical Issues of Enterprise Information Systems II Volume 1, eds. L. Xu, Tjoa A., Chaudhry S. (Boston: Springer), pp. 145-152. 
this modern model technology to systems analysis, afford many kinds of administer information, strengthen the ability of decision-making and sustain, flexible, optimize and dynamic ability to meet emergency of ERP. On the other side, as to I/O model, it also combines with strongly ERP , making use of the company technology to real time manage mass of information in enterprise, strengthen its maneuverability in enterprise, achieving the predominance mutualism.

To implement the aims just referred, many problems should be settled first. The chief problem is the feasibility of the associative of ERP and $\mathrm{I} / \mathrm{O}$ technology. As to I/O model, through accounting and analysis of the manufacture course, make plans of the enterprise, as well as offering some bases on enterprise decision-making, the first thing is to make $1 / O$ table, which is the key and foundation to utilize $1 / O$ model. But how to get data conveniently and truly is the key to make $\mathrm{I} / \mathrm{O}$ table. From the research discover, the ERP logic ,which is the foundation of ERP, has huge comparability with consume relationship of $1 / O$ Table in principle, can implement the conversion between ERP foundation data and I/O table, which assure the feasibility of directly make $\mathrm{V} / \mathrm{O}$ table from the ERP intrinsic data and make ground for the further research.. This paper will discuss this topic.

ERP has been widely used by manufacture enterprise as an information system recently. Meanwhile, the research on machine enterprise $\mathrm{V} / \mathrm{O}$ model is mature. This paper studies the relationship between ERP logic and the direct consume coefficient of machine enterprise $\mathrm{I} / \mathrm{O}$ table, and proves that converting basic data of ERP to direct consume coefficient and entire consume coefficient of enterprise $\mathrm{I} / \mathrm{O}$ table is feasible. And it is also feasible using the basic data of ERP to make the $\mathrm{I} / \mathrm{O}$ table, to analyze and improves decision.

\section{ERP LOGIC, RELEVANT DEMAND, CONSUME OF ENTERPRISE I/O TABLE}

Doctor Joseph A. Orlicky, IBM, divide materiel into Independent demand and Dependent demand. He thought the materiel requirement in product framework is relevant.In his theory, it contract accessory discreteness、 parts、whole、 raw and processed materials, considering different materiel has different match relation. And, bring time subsection into materials stock station. On the bases of main manufacture plan, bill of materiel and stock station, make sure of the demand time-sharking. MRP in 60s, closed loop MRP in 70s, MRPII in 80s and ERP in 90s are all based on this. Thus, no matter how strong the ERP is, the base of it is relevant demand theory.

Material requirement planning is not only a technique for planning "material" requirements. It is also a logic that relates all the activities in a company to customer demands. People can manage all the resources in a company by using MRP logic together with data processing in other areas. This entire system is called a Manufacturing Resources Planning System, or MRP II. With the introduction of technological enhancements such as open systems platforms and client/server architecture, MRP II systems are now evolving into Enterprise Resource Planning Systems (ERP). An ERP system plans not only the allocation of manufacturing 
resources but also other resources, and has applications in service as well as manufacturing industries.

Nature of Demands All systems are implemented to satisfy customers' demand. There are different sources of demand for a product and its component items. Some item requirements are determined by the needs of other items while others are specified by customers. The former requirements also come from customers, but indirectly. Item requirements can be classified as dependent and independent demands.

Independent demand Demand for an item that is unrelated to the demand for other items. Demand for finished goods, parts required for destructive testing, and service part requirements are examples of independent demand.

Dependent demand Demand that is directly related to or derived from the bill of material structure for in other items or end products. Such demands are calculated and need not be forecasted. Concretely to say, the relevant demand means that, a kind of materiel demand is directly relevant to another kind, or can be directly calculated by other materiel. In ERP, relevant demand embodied by product framework, while product framework is described by BOM (Bill of Material). So, BOM (Bill of Material ) is important data in ERP, it embodies the relationship among finally items and the parts, the module, the accessory and raw and processed materials.

As for this case, from the BOM, we can conclude that when produce a ball-pen, it will cost a ball-hat. However, when produce a ball-hat, it will cost $0.005 \mathrm{~g}$ PE, others can analogy like this. Thus, we can get all the costs if we produce a ball-pen (the parts, the module, the accessory and raw and processed materials, frock mould). But all the functional modules in ERP contain produce and manage module, stock module, repertory manage module, finance manage module, which were built on basic data. So we can say ERP is the same with the produce condition that making accessories into output when considering enterprise's type. MRP is a Manufacturing Resources Planning System of parts. As long as to make out the main manufacture plan, any manufacture enterprise can use MRP.

So from the analysis, the Consume relation detonated among materiel by BOM has the following characteristics.

1) Consume relation among materiel is unilateralism. Any machine manufacture produce can be described like the parts, the module, the accessory and framework of raw and processed materials. Consume relation detonated among materiel is from the top down. For example, the accessory as the most important portion, only cost raw and processed materials, but not modules v parts 、 and finished product. Modules cost only accessory and raw and processed materials but not parts. Others like this.

2) Consume dosage among materiel is indicated in substantiality, show every connection of quantity dependence, all use substantiality as unit.

3) Manufacture framework and Consume relation is each independent but between then are associate. From chart 1, Manufacture framework reflects machine manufacture enterprise layered product framework and organizing character, which framework is dendriform, having father item, children item. Similarly, BOM can be expressed like multilayer BOM, but also father item, children item BOM, which distinctly describe the constitution and consume of every accessory, parts, and module. When detached, they each have its absolute system. Ball-pen's components ball-hat's BOM, and ball-core, writing skill also have their monolayer BOM. 
4) BOM not only describes the Consume relation among materiel, but also describes the Consume relation with frock mould during the materiel process.

5) BOM has greatly agility. When designing software, it can add attribute when necessary. Whether the attributes are abundant and complete is an important scale to measure whether ERP is strong.

\section{MACHINE MANUFACTURE ENTERPRISE SUBSTANTIAL I/O TABLE AND CHARACTERISTIC}

The $\mathrm{I} / \mathrm{O}$ table of enterprise is based on the manufacture characteristic and using require. Setting corresponding module in the table to describe the consume and occupy in every resource by Self manufacture. Commonly, it is need to set (1) Consume relation matrix about self manufacture to self manufacture to describe the technical and economic contact among them; (2)Consume relation matrix about self manufacture to external manufacture to describe the consume relation of external manufacture.; (3) Consume relation matrix about self manufacture to charge to describe the consume relation to charge; (4) Consume relation matrix about self manufacture to manufacture equipment and hour to describe the consume relation to equipment and hour.

Compared with other enterprise, machine manufacture enterprise have some vivid characteristic : (1) The output of machine manufacture enterprise is mostly assembling framework, to be divided into four layers, accessory, parts, module, and complete product according to process. Their execution process is in layer and sequence. Their consume relation is unilateralism, no converse contact. (2) The complexity of machine manufacture is mainly behaved into accessory ,module, parts and the variety of the technology. Accessory is different with the framework and the capability, its process arts and flow are different. (3) The character of the machine process is the consume of energy sources, frock module and labor hour mostly happen with carrying equipment, the equipment can be divided into currency and expert. (4) Besides process hours, tool, apparel, mole, jamming of cartridge and mould (can be called by a joint name frock mould) are absolutely necessarily in machine manufacture enterprise, a great deal of them is made by enterprise itself. (5) the reckon of machine manufacture enterprise is too great, from the request of management, it is necessary to account exactly the consume by every process and frock mould to element and the cost .

Table 1 is machine manufacture enterprise substantial $1 / O$ table. It contains 6 matrixes. (1) self manufacture $X$ self manufacture consume relation matrix. Self manufacture is divided into four layers according to the characters of machine manufacture enterprise, accessory, parts, module, and complete product according to process. (2)self manufacture $\times$ frock mould consume relation matrix., to describe the consume relation of frock mould. (3)self manufacture $\times$ raw and processed materials consume relation matrix, to describe the consume relation to raw and processed materials, which only behaved by accessory. (4) self manufacture $\times$ energy sources 
A Study on Relationship Between ERP Logic and Direct Consume Coefficient of I/O Table

consume relation matrix, to describe the consume relation to energy sources. It mostly happen with carrying equipment. (5)self manufacture $\times$ labor hour consume relation matrix, to describe the consume relation to labor hour. (6) self manufacture $X$ equipment process hour consume relation matrix, to describe the consume relation to equipment.

If $a_{i j}$ express dosage when yielding unit materiel ${ }^{j}$.( substantiation)

In I/O model, direct consume coefficient express the consume to product and labor when manufacturing unit substantial product. For example the self manufacture $x$ self manufacture direct consume coefficient matrix:

$$
\widetilde{a}_{i j}=\widetilde{q}_{i j} / \widetilde{Q}_{j} \text { express the dosage of substantial product } i \text { when yielding unit }
$$
materiel $j$

$\widetilde{a}_{i j}$ is direct consume coefficient about $\mathrm{j}$ to $\mathrm{i}$, express the dosage of substantial product $i$ when yielding unit substantial product $j \widetilde{Q}_{j}$ is the output of $\mathrm{j}$ during the reporting period. Other direct consume coefficient in direct consume matrix are analogized like this.

Table 1. Machine Manufacture Enterprise Substantial I/O Table

\begin{tabular}{|c|c|c|c|c|c|c|c|}
\hline \multirow{2}{*}{ output } & \multirow[t]{2}{*}{ Input } & \multicolumn{4}{|l|}{ Interspace } & \multirow{2}{*}{$\begin{array}{l}\text { Finally } \\
\text { product }\end{array}$} & \multirow{2}{*}{$\begin{array}{l}\text { Totally } \\
\text { output }\end{array}$} \\
\hline & & accessory & module & parts & $\begin{array}{l}\text { complete } \\
\text { product }\end{array}$ & & \\
\hline \multirow{4}{*}{$\begin{array}{c}\text { self } \\
\text { manufacture }\end{array}$} & accessory & \multirow{4}{*}{$q_{i j}$} & & & & \multirow{4}{*}{$\tilde{\gamma}^{i}$} & \multirow{4}{*}{$\widetilde{Q}_{i}$} \\
\hline & module & & & & & & \\
\hline & parts & & & & & & \\
\hline & $\begin{array}{l}\text { complete } \\
\text { product }\end{array}$ & & & & & & \\
\hline \multicolumn{2}{|c|}{ frock mould } & $\tilde{Z}_{i j}$ & & & & & \\
\hline \multicolumn{2}{|c|}{$\begin{array}{c}\text { raw and processed } \\
\text { materials }\end{array}$} & $\widetilde{G}_{i j}$ & & & & & \\
\hline \multicolumn{2}{|c|}{ energy sources } & $\widetilde{W}_{i j}$ & & & & & \\
\hline \multicolumn{2}{|l|}{ labor hour } & $\widetilde{T}_{1 i j}$ & & & & & \\
\hline \multicolumn{2}{|c|}{ equipment process hour } & $T_{2 i j}$ & & & & & \\
\hline
\end{tabular}

If $\widetilde{b}_{i j}$ express the total dosage of product $i$ when yielding unit self manufacture $j$

$\tilde{b}_{i j}=\tilde{a}_{i j}+\sum_{k=1}^{n} \widetilde{a}_{i k} \widetilde{a}_{k j}+\sum_{s=1}^{n} \sum_{k=1}^{n} \tilde{a}_{i s} \widetilde{a}_{s k} \tilde{a}_{k j}+\cdots \cdots \quad i . j=1,2 \cdots n$ 
$\widetilde{a}_{i j}$

is direct consume coefficient, the latter are first second.......indirect consume coefficient, using $k, s \cdots$ as agency. As to table 1 , the equation above first quadrant can be written like matrix as follows:

$\widetilde{B}=\widetilde{A}+\widetilde{A}^{2}+\widetilde{A}^{3}+\widetilde{A}^{4}+\cdots=(I-A)^{-1}-I$

$\tilde{A} 、 \tilde{B}$ are direct consume coefficient matrix and totally consume coefficient matrix

\section{THE RELATION AND TRANSFORM BETWEEN ERP LOGIC AND CONSUME COEFFICIENT}

From the analysis above, Machine manufacture enterprise substantial $\mathrm{V} / \mathrm{O}$ model is emphasize produce and process, recognize product as analyze object. Every element in matrix in table 1 separately described the consumption and occupy of the self manufacture to kinds of resources during the process. ERP is built on the bases of independent demand and dependent demand. ERP system plans not only the allocation of manufacturing resources but also other resources, and has applications in service as well as manufacturing industries. In nature, both are coherent. We can reduce them into table 2 .

Table 2. ERP Logic and Enterprise Substantial I/O Model

\begin{tabular}{|c|c|c|}
\hline Element & ERP logic & Enterprise substantial I/O model \\
\hline Industry & $\begin{array}{l}\text { Machine manufacture } \\
\text { enterprise }\end{array}$ & Machine manufacture enterprise \\
\hline $\begin{array}{l}\text { Expressing } \\
\text { element }\end{array}$ & $\begin{array}{l}\quad a_{i j}: \quad \text { express dosage } \\
\text { when yielding unit materiel } \\
j\end{array}$ & $\begin{array}{l}\quad \widetilde{a}_{i j}=\widetilde{q}_{i j} / \widetilde{Q}_{j} \quad \text { express the } \\
\text { dosage of substantial product } i \\
\text { when yielding unit materiel } j\end{array}$ \\
\hline Express & $\begin{array}{l}\text { Consum relationship } \\
\text { among meteriel and to all } \\
\text { kinds of resources }\end{array}$ & $\begin{array}{l}\text { The consume and occupy of self } \\
\text { manufacture to all kinds of } \\
\text { resources }\end{array}$ \\
\hline Source & Dosage attribute in BOM & $\tilde{a}_{y}=\tilde{q}_{\eta} / \tilde{Q}$, \\
\hline $\begin{array}{l}\text { Express } \\
\text { mode }\end{array}$ & Substantiation & Substantiation \\
\hline $\begin{array}{r}\text { Consume } \\
\text { relationship }\end{array}$ & Unilateralism & Unilateralism \\
\hline $\begin{array}{l}\text { To totally } \\
\text { consume }\end{array}$ & No describetion & $\begin{array}{l}\text { Described by total consume } \\
\text { coefficient }\end{array}$ \\
\hline
\end{tabular}

There is the relationship above, so we can clearly to elicit:

$\widetilde{a}_{i j}=a_{i j}$ 
Thus, in practicality handle, we can use BOM in ERP to directly transform into direct consume coefficient $A$ in $\mathrm{I} / \mathrm{O}$ table. And we can get $B$ from $B=(I-A)^{-1}$.Using ball-pen as an example, we get direct consume coefficient matrix when transform the BOM. Then we can get the totally consume coefficient matrix. It is easy in computer.

The characters when transforming into direct consume coefficient from BOM:

1) Through ERP data sharing and transforming directly, we get the direct consume coefficient in the quadrants in enterprise substantial $\mathrm{I} / \mathrm{O}$ table. They are in reason, and the results are right and feasible.

2) Through transforming, we can use another mode to describe the direct consume relation, which is avail to plan the manufacture. Using pen-core for example, from the rows, besides ball-pen is 1 , other direct consume coefficient to pen-core is 0 . From the lines, ball-core has consumed to pinpoint, pen-oil, pen-pipe and pen-core assemble center, there are 1 piece, $0.002 \mathrm{~kg}$, 1 piece, and $0.0025 \mathrm{~kg}$. The whole direct consume coefficient express all materiel's consume to other resources and other materiel.

3) From direct consume coefficient matrix $A$ we can get totally consume coefficient matrix $B$. Direct consume coefficient matrix describe all materiel's consume to other resources and other materiel during the process, which is avail to plan the manufacture. Totally consume coefficient matrix describe the all materiel's consume to all the other materiel during the process. Using ball-pen for example, the most right line describe he all materiel's consume to all the other materiel during the ball-pen process. It describe the substance consume relation during the process in another angle, which is avail to manage analyze and make decision.

4) The course of ERP foundation data transforming into direct consume coefficient is exact and rapid.

5) We can go on manage sustain and decision-making sustain, for example, whole cost reckon and analyze, fix a price, consume analyze, balance the ability of equipment

\section{CONCLUSIONS}

Using enterprise $\mathrm{I} / \mathrm{O}$ model to calculate and analyze the process, and to offer thereunder for enterprise when making decision, the first thing is make $\mathrm{I} / \mathrm{O}$ table, which is the key and foundation to utilize $\mathrm{I} / \mathrm{O}$ model. This paper studies the relationship between ERP logic, discuss the feasibility when transforming the ERP foundation data into the direct consume coefficient and totally consume coefficient in I/O table. We can see, if the products are complex and various, this transform can converse mass data into the corresponding element in $\mathrm{I} / \mathrm{O}$ table and making table automatically according some rules. And, the transformed $\mathrm{I} / \mathrm{O}$ table can contain more things than ERP foundation data. Meanwhile, utilizing the analyis and account of $\mathrm{I} / \mathrm{O}$ model, we can get the data to sustain manage decision. This study makes ground for further research. 


\section{ACKNOWLEDGEMENTS}

This research has been partially supported by grants from National Natural Science Foundation of China (No. 70501030 and Innovation Group 70621001), and Beijing Natural Science Foundation of (No.9073020).

\section{REFERENCES}

1. J.E. Hunton, B. Lippincott, and J.L. Reck, Enterprise resource planning systems: comparing firm performance of adapters and nonadapters, International Journal of Accounting Information Systems. Number 4, pp.165-184, (2003).

2. A. Lee, Researchable directions for ERP and other new information technology, MIS Quartely. Volume 24, Number 1, pp.3-7, (2000).

3. V.A. Mabert, A. Soni, and M.A. Venkataraman, Enterprise resource planning survey of US manufacturing firms, Production and Inventory Management. Volume 41, Number 2, pp.52-58, (2000).

4. P. Bibgi, M.K. Sharma, and J.K. Godla, Critical Issues Affecting an ERP Implementation, Information System Management. Volume 16, Number 3, pp.7-14, (1999).

5. R.J. Murray and D.E. Trefts, The IT Imperative In Business Transformation, Information System Management. Volume 17, Number 1, pp.1-6, (2000).

6. T. Rencheng, The Input-Output Table with Two Factors, Chinese Economic Planning and Input-Output Analysis (Oxford Univ. Press), p.19. 